\title{
O PODER DO TRAÇO DE CHRISPIM DO AMARAL
}

\author{
THE POWER OF CHRISPIM DO AMARAL'S DRAWING
}

\section{Raúl Gustavo Brasil Falcón UEA}

\section{Resumo}

Este trabalho teve por objetivo realizar um estudo da produção gráfica do artista Chrispim do Amaral (1858-1911), particularmente das caricaturas produzidas para a revista A Semana llustrada (1887) e O Estafeta (1879) em Belém. No conjunto de caricaturas da revista, foram observadas diversas cenas e relatos da sociedade belenense do século XIX - aproximando da realidade nacional, criticando de maneira divertida e jocosa as situações políticas e acontecimentos históricos da sociedade paraense.

\section{Palavras-chave:}

Chrispim do Amaral; Caricatura; Semana Ilustrada.

No século XIX ocorreram diversas transformações na indústria, nos meios de transportes e na propagação e facilitação das informações pela mídia impressa. Um olhar para o passado nos faz refletir sobre como se perpetuaram os costumes da sociedade brasileira em meio a tantas transformações políticas e culturais de um determinado sítio. A obra gráfica no periódico O Estafeta (1879) e A Semana llustrada (1887) publicada ambos em Belém, pelo artista Chrispim (1852-1911) do Amaral, é um marco para a grande produção de caricaturas no Norte do país. Uma fonte inesgotável de relatos, informações que cercam os hábitos da sociedade belenense, podendo até se estender para uma realidade nacional, visto que os problemas sociais e situações que eles descrevem não são exclusividade do Norte. Vicente Salles ${ }^{1}$ já explorou a temática da caricatura no Pará em seus diversos artigos, evidenciando a importância da produção das artes gráficas no local. A importância para destacar o trabalho realizado por Chrispim do Amaral apresenta uma grande produção cultural realizada nas cidades nortistas do país. Revela a influência da cultura europeia no comportamento da sociedade brasileira, com a tentativa de tantos em se equiparar aos valores culturais das classes

\section{Abstract}

This work had as objective of studying the graphic production of the artist Chrispim do Amaral (1858-1911), specially the caricatures made for the 'A Semana llustrada' magazine and 'O Estafeta' (1879) from Belém. Several scenes and reports of the 19th century Belém society were observed - aproaching the national reality, amusingly and jokingly criticizing the political situations and historical events of Pará society.

Keywords:

Chrispim do Amaral; Caricature; A Semana Ilustrada.

dominantes - e é nesse ponto que entra a caricatura. Procuramos entender da seguinte maneira: a chegada da corte portuguesa no Brasil no ano de 1808 acarretou profundas transformações políticas - de colônia, este Estado passa a ser sede da monarquia, e posteriormente um reino. Oliven (2001) ressalta que os processos de transformações políticas em nosso país acarretaram uma mudança de comportamento na sociedade brasileira, em especial no Rio de Janeiro, "onde a família real vivia e que, por isso, tornou-se uma cidade "cosmopolita", na qual pessoas abastadas tentavam se comportar de uma maneira que elas supunham ser europeia" (OLIVEN, 2001, p. 03). No Brasil, a modernidade ${ }^{2}$ frequentemente era vista (ainda é) como algo que vem de fora e que deve ser admirado e adotado (Idem). A caricatura de Chrispim do Amaral surge em um momento de decisões importantes para o país, que vai desde a abolição da escravidão, o fim da monarquia e início da primeira república.

Caricaturar os hábitos provincianos e mostrar as mazelas da escravidão através de seu traço foi uma luta e expressão de liberdade, "com suas armas: o lápis e a pena, para transformar a sátira 
no cautério mais enérgico" (SALLES, 1992). Salles salienta o trabalho de Chrispim do Amaral, em torno de uma sociedade local, extremamente heterogênea e preconceituosa: Com a sua corte de novos ricos que macaqueavam futilidades mundanas parisienses, era bem a superfície em que a pena moralizadora do pasquim deveria juntar-se ao lápis e funcionar como instrumentos cirúrgicos. [...] o jovem Chrispim se contentaria, nessa faixa com as ridicularias sociais, na faixa da sociedade que vivia, sabia usar da sátira com um fim moralizador ${ }^{3}$. A expressão através da arte da caricatura assume então um carácter revolucionário. A arte está ligada ao rompimento de uma realidade, aproximando-se da libertação - toda obra de arte pode ser revolucionária em diferentes aspectos, podendo subverter estilos ou formas de compreensão dominantes sobre a arte (MARCUSE, 2007, p. 17 apud VASCONCELOS, 2019, p. 13). Para Pereira (2006), a imagem é detentora da reação do homem em meio do espaço em que vive, subsiste em seu processo de produção de imagens como expressão devendo ser levado em consideração os estudos de emancipação nos aspectos culturais, econômicos, políticos, ideológicos e sociais (PEREIRA, 2006, p. 34). Voltemos para o Brasil no século XIX, em que a maneira de emancipação para o problema de expressão das classes desfavorecidas no campo artístico é expressa com intensidade a partir da história do humor gráfico, presente nas revistas ilustradas, que atendiam a uma necessidade de entreter, dialogar e formar opiniões através da imagem e texto, transformando o pensamento fracassado - o humor surge como um recurso para representar e criticar o comportamento de grupos de uma sociedade elitizada e opressora (QUEIROZ, 2010, p. 14). Para Joly (2007) a imagem sempre esteve presente na vida humana. A criação da imagem é uma necessidade de expressão do homem-um processo de expressão e comunicação, a imagem é um meio de comunicação que está presente desde os primórdios do homem:

No início, havia a imagem. Para onde quer que nos viremos, existe a imagem. Por todo o lado através do mundo, o homem deixou vestígios das suas faculdades imaginativas sob a forma de desenhos feitos na rocha e que vão desde os tempos mais remotos até a época moderna. Estes desenhos destinavam-se a comunicar mensagens e muitos deles destinavam-se a comunicar mensagens e muitos deles constituíram aquilo a que chamamos "os pré-anunciadores da escrita" utilizando processos de descrição e representação que apenas retinham um desenvolvimento esquemático de representações reais (JOLY, 2007, p. 18).

A função da imagem é um instrumento de comunicação entre as pessoas, pode servir também como intercessão entre o homem e o próprio mundo: “como produção humana destinada a estabelecer uma relação com o mundo" (Idem). A necessidade de retratar traços fisionômicos exagerados, para Charles Baudelaire (1998) começa com o que está diante de nossos olhos, e o homem acaba por se assemelhar aquilo que gostaria de ser representados em belo e feio - a função da caricatura é dupla: o desenho e a ideia, o desenho violento e a ideia sarcástica e velada, revelada através do riso. Seus problemas, suas cóleras e seus sofrimentos são expressos no traço, e ao observamos as caricaturas realizadas por Chrispim do Amaral e pelos demais artistas a caricatura sempre estava interligada com os problemas humanos. "O que não agrada, envergonha, é transformado em grotesco" (BAUDELAIRE, 1998, p. 19), para Baudelaire (1998) observou na comicidade, no ponto de vista artístico, uma imitação, grotesco, uma criação. O cômico é uma imitação mesclada de uma faculdade criadora, ou seja, de uma idealidade artística, relacionada com a faculdade imitadora de elementos preexistentes na natureza (Idem).

Chrispim do Amaral (1852-1911) nasceu em Olinda, Pernambuco, foi pintor, escritor, caricaturista, cenógrafo, ator, músico, e outras várias atividades que desempenhou no Brasil. É imprescindível, de início, falar que era negro e viveu numa época onde a cor da pele era determinante dentro da sociedade. Chrispim do Amaral, entretanto, rompeu essas barreiras e se mostrou tão importante no cenário artístico brasileiro quanto os demais que viveram em seu tempo.

Ao nos debruçarmos sobre sua vida nos deparamos com uma série de informações a respeito de luta pelos seus direitos e ideais políticos. Fundou duas importantes revistas de cunho satírico - A Semana Ilustrada (1887), em Belém do Pará, e O Malho (1902), no Rio de Janeiro, atuando nelas através da escrita e do desenho, Chrispim estudou com diversos artistas, chegando a morar na Europa, buscando aperfeiçoar-se na sua arte e procurando reconhecimento dentro de uma sociedade que ditava aceitação através dos cânones artísticos. 


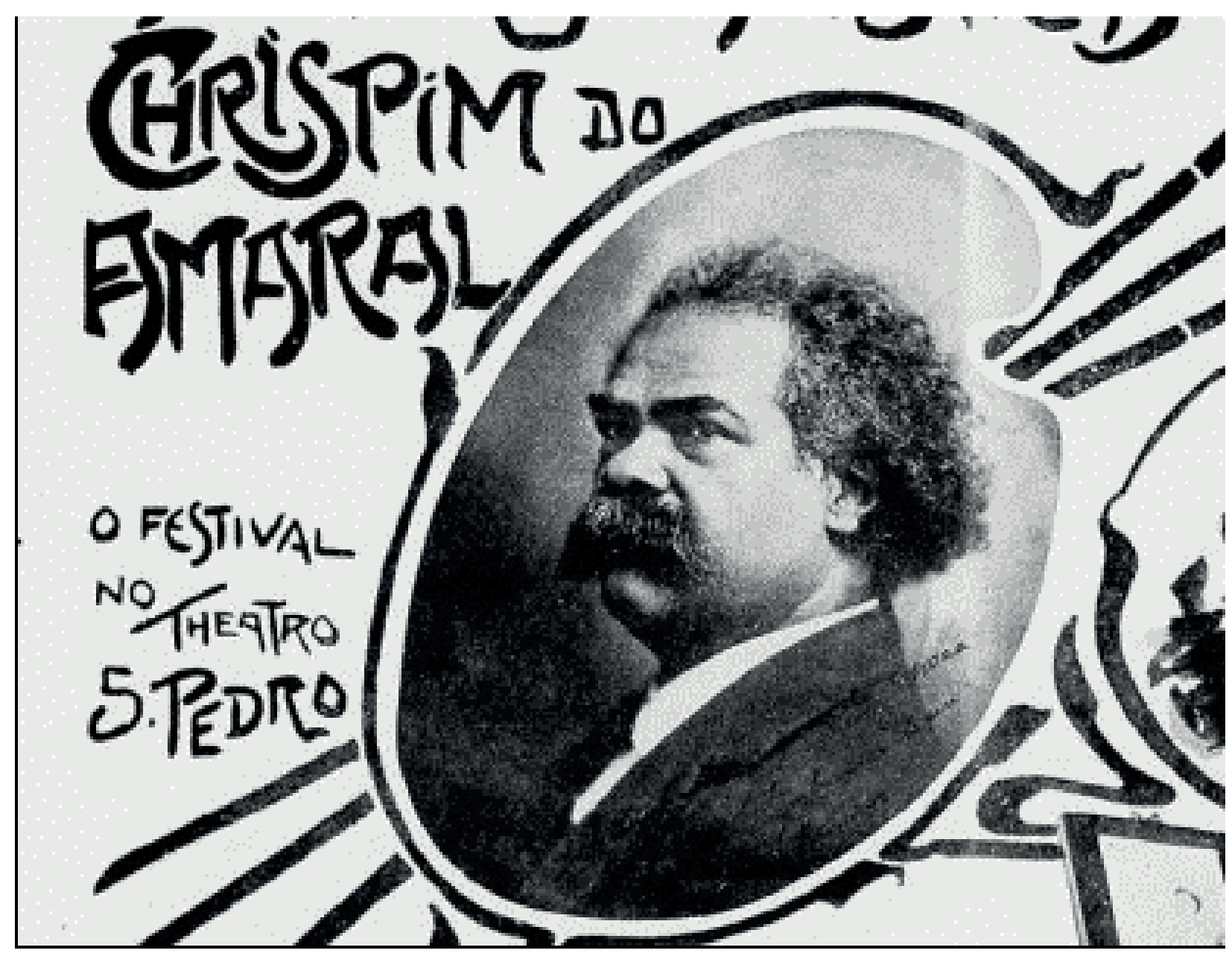

Figura 1 - Chrispim do Amaral. Fonte: Revista da Semana ed. 6. 11 de dezembro de 1912. Rio de Janeiro. Homenagem à Chrispim do Amaral.

No começo do século XIX artistas negros e mulatos tinham que competir contra o preconceito racial para desenvolver suas atividades fora do âmbito que lhes era reservado. Embora já houvesse discursos, protestos e defesa em favor dos negros, a mentalidade em relação da atuação do negro na sociedade ainda era muito desanimadora. A autora Celia M. de Azevedo, em sua obra Onda Negra Medo Branco (1987), relata através de documentos e periódicos a atuação do negro no Brasil no período pós-abolição e a crescente imigração de trabalhadores europeus. Em seu texto, sobre denúncia e racismo, temos o seguinte relato: "Na festa da Boa Morte, em Limeira, apreciamos a música sendo regido pelo Marques, ele pretinho maneando a batuta e chamando a diversos brancos, músicos, a obediência do compasso. [...] Que grande coisa é a inteligência!" (AZEVEDO, 1987, p. 239).
Um músico regente e negro comandando uma orquestra de homens brancos. Azevedo (1987) ressalta que notavelmente há uma inversão do tradicional branco sobre o negro. "Negro, porém inteligente. Negro só é reconhecido provando que desde que seja dotada de saberes e que estes sejam reconhecidos pelos brancos, o negro pode sobressair socialmente" (Idem).

Após a abolição, a proclamação da República quase nada contribuiu para a melhoria dessa situação. Para Leite (1940), negros e mulatos foram entregues ao seu próprio destino, tendo de competir em condições de grande desvantagem com a recente mão-de-obra trazida da Europa, e ainda pesando sobre si o "implacável preconceito racial, ostensivo ou o mais das vezes mal dissimulado, não admira que nossos melhores artistas negros ou mulatos tenham levado a existência miserável" (LEITE, 1940, p. 15). Ainda 


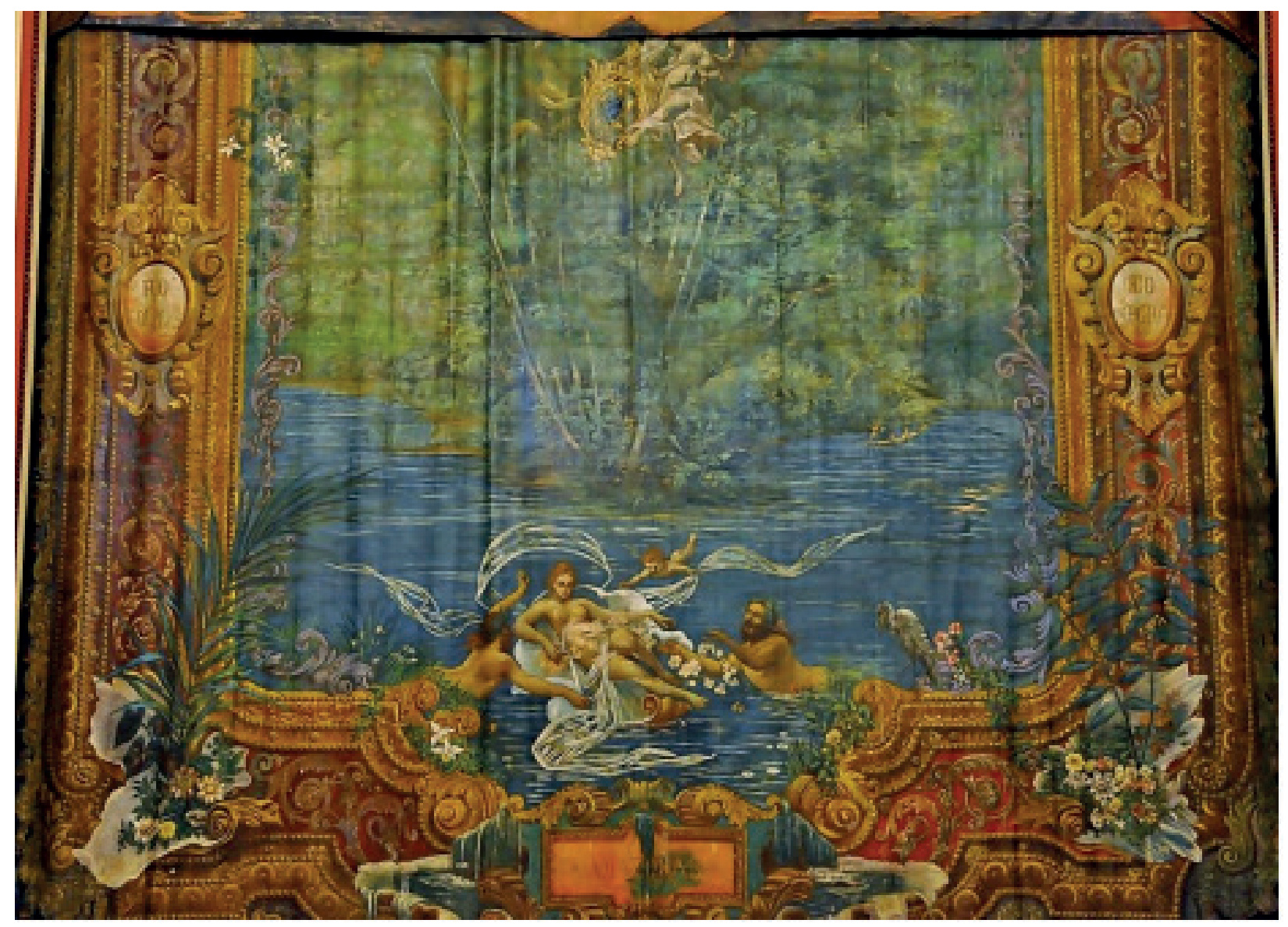

Figura 2 - Pano de Boca do Teatro Amazonas atribuído a Chrispim do Amaral (1858-1911). Óleo sobre lona crua 10,50m X 6,40m. Sala de espetáculos do Teatro Amazonas. Fonte: Acervo pessoal.

houve no Brasil uma busca para se equiparar aos centros hegemônicos, como a França ocorrendo então o remodelamento do espaço urbano e social das cidades brasileiras, afastando geograficamente os negros e mulatos do espaço da elite dos brancos. É nesse momento que a figura de Chrispim do Amaral aparece destoante no cenário artístico e cultural de importantes cidades, como as cidades nortistas de Manaus e Belém, além de Recife e Rio de Janeiro. Essas conquistas que ele obteve certamente decorreram da busca pela aprovação nos grandes centros que Ihe poderiam abrir as portas.

Durante o século XIX as cidades de Manaus e Belém viveram o seu apogeu econômico graças à extração e à comercialização do látex da árvore Hevea Brasilienses, mais conhecida como a seringueira. Com o crescimento da economia, ocorreram significativas mudanças no cenário arquitetônico e social e na vida da população dessas cidades. Belém e Manaus foram as duas principais cidades que se beneficiaram dessa comercialização, e entre os maiores símbolos que representam sua riqueza estão o Teatro de Nossa Senhora da Paz e o Teatro Amazonas. Atraídos por esse boom econômico que cercou o Norte do país, muitos artistas - como decoradores, desenhistas, pintores, escultores - se dirigiram para essas cidades em busca de melhores oportunidades. Foi entre esses artistas que se destacou o jovem pernambucano Chrispim do Amaral. Conhecido por seus variados talentos chegou à cidade de Belém aos dezoito anos, junto com a Companhia Teatral de Vicente Pontes de Oliveira, permanecendo durante seis anos na capital paraense e logo em seguida partiu para Manaus, chegando a trabalhar como decorador nos teatros locais. Na cidade de Manaus foi contratado pelo governador do Amazonas, Eduardo Gonçalves Ribeiro, que Ihe incumbiu dos serviços de decoração do Teatro Amazonas. Ficou encarregado da aquisição da mobília, 
mecanismo do palco, confecção do pano de boca ${ }^{4}$ e a subcontratação dos artistas italianos para a decoração do salão nobre.

Teixeira Leite cita que Amaral retornou a sua cidade natal por poucos meses e em seguida voltou a Belém, onde residiu por mais dois anos, de onde posteriormente partiu para a França (LEITE, 1940, p. 143). Em Paris, trabalhou em um dos jornais humorísticos mais prestigiados da época, $L a$ Caricature. No jornal francês a sua desenvoltura com caricaturista é notável. Em uma de suas publicações ficou internacionalmente famoso com a charge Dum-Dum, "representando a rainha Vitória presa, como uma criancinha, debaixo do braço de Paul Kruger, que Ihe sofraldava a saia e batia palmada" - a caricatura fazia alusão às balas explosivas do exército inglês e uma das primeiras derrotas britânicas. A divertida charge infelizmente the causou um processo $0^{5}$ da justiça francesa contra o editor e o caricaturista, sendo condenado a três anos de prisão (Idem).

Logo após a esse escândalo, retornou para o Brasil antes mesmo de cumprir a sentença. No Rio de Janeiro desempenhou diversas funções como cenógrafo e retomou a sua carreira jornalística fundando diversos jornais como O Malho (1902), A Avenida (1903) e o Pau (1905).

\section{O ESTAFETA}

A mídia impressa nessa altura (1887) já se consolidava como um grande veículo de comunicação e de livre pensamento sobre uma grande diversidade de problemáticas sociais. Os desenhos realizados por Chrispim do Amaral elucidam uma série de comportamentos, do povo e cada época, anúncios de lojas, e fazem crítica política ao que ocorria na sociedade do século XIX. Utilizando a técnica de caricaturar - exagerar os traços fisionômicos característico da figura com a intenção de divertir, criticar e reportar.

No ramo jornalístico, de acordo com Salles (1991, p. 09), o jornal O Estafeta, publicado em 1879 , na cidade de Belém, tem como edição e lançamento do próprio Chrispim do Amaral. Com desenhos bem feitos, traços firmes e precisos, desenhava figuras humanas - personalidades da época, e aplicava em segundo plano espaços da cidade de Belém. Influenciado pela litografia do alemão Karl Wiegandt ${ }^{6}$ e do caricaturista Angelo Agostini, o jornal apenas contou com

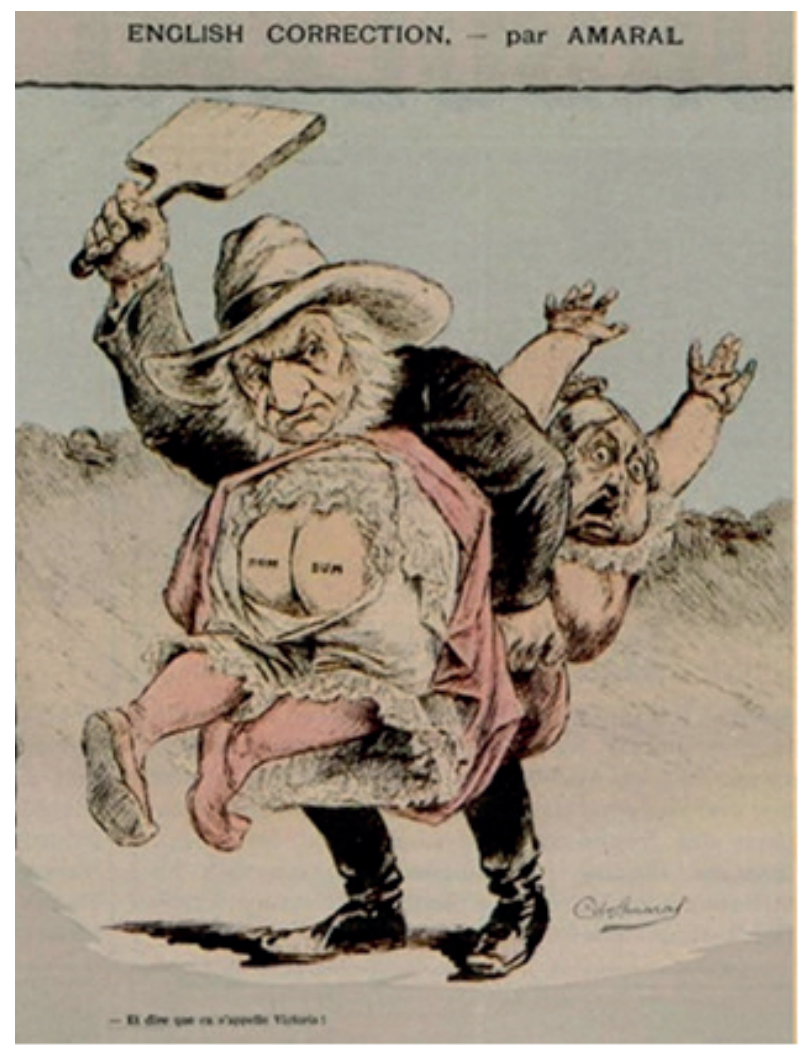

Figura 3 - Dum-dum. Caricatura da Rainha Vitória, reeditada e republicada no jornal francês $L e$ Petite Journal em 20 de agosto de 1905.

apenas duas edições, marcando o surgimento do artista no universo das caricaturas. As assinaturas que Chrispim do Amaral adotou, inicialmente, na primeira publicação de $O$ Estafeta foram identificadas somente por um $X$. Logo na segunda edição, ele adota o pseudônimo de Puck. A escolha de Puck não é por acaso - é um dos personagens de Willian Shakespeare no conto Sonho de Uma Noite de Verão; um ser mitológico que habita nas florestas, de caráter brincalhão e travesso:

Eu sou, realmente, o ledo vagabundoso noturno que brinquedo faço tudo, porque a todo instante de Oberon deixo alegre o semblante. Como ele ri gostoso, ao ver o efeito, sobre um cavalo gordo, do meu jeito de relinchar qual égua jovem e calorosa. [...] A sábia tia às vezes, numa história de enredo triste e perenal memória, pensa me ter, qual banquinho à mão; então me afasto, e bum! Vai ela ao chão, e enxertando na história um dispare reclame em altas vozes o alfaiate, sem parar de tossir. Em gargalhadas as comadres rebentam, de malvadas, saltam de gozo e juram, da janela, não terem visto uma hora como aquela (SHAKESPEARE, Willian. Sonho de uma Noite de Verão. Tradução de Jean Melville. Editora Martin Claret: São Paulo, 2005, p. 27). 


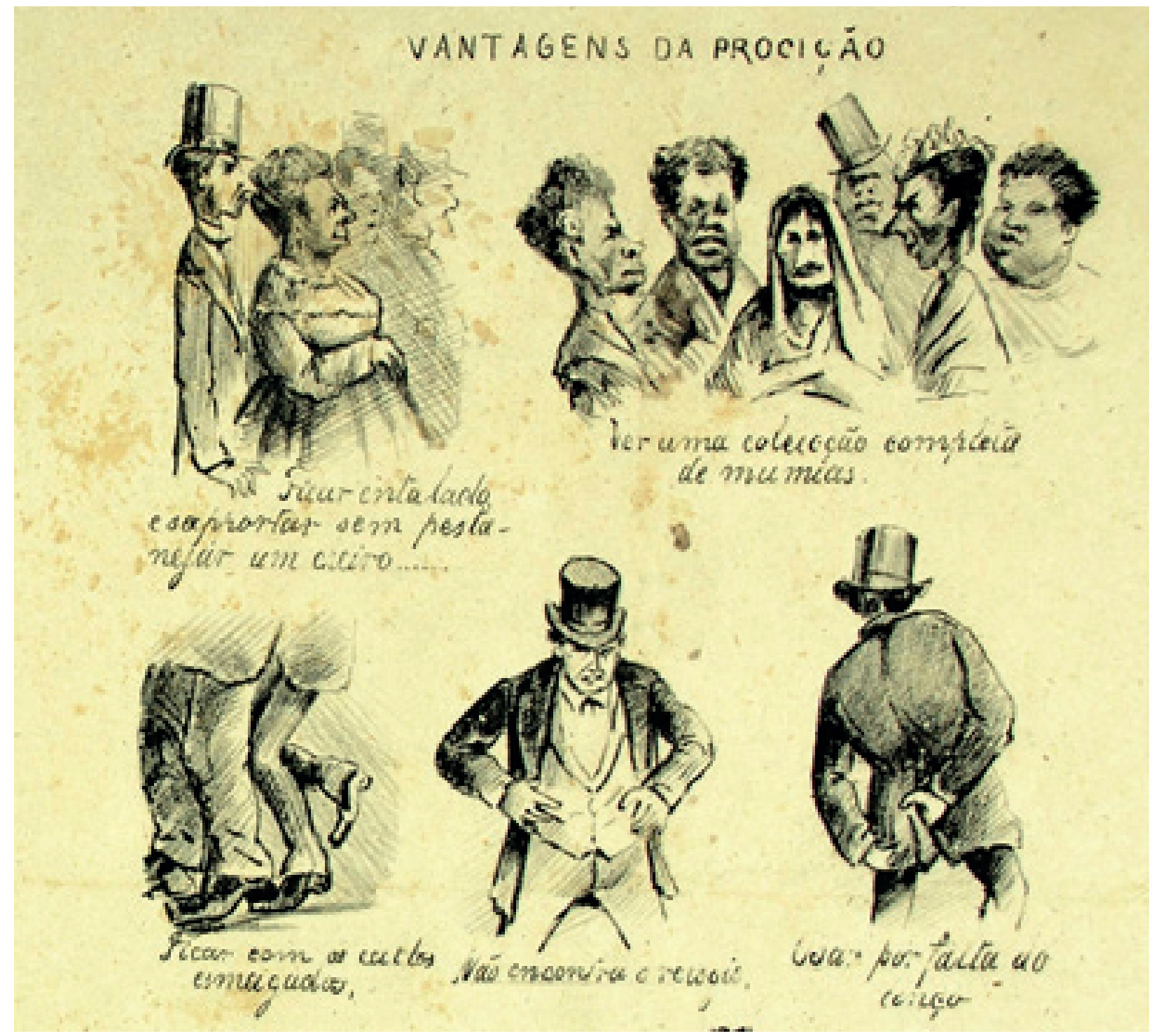

Figura 4 - Vantagens da Procissão. Fonte: O Estafeta (1887) Ano 1, n. 1.

Através da obra gráfica de Crispim do Amaral nos deparamos com as inquietudes e problemas que ocorriam na sociedade do século XIX. Uma das maneiras de mostrar e criticar a sociedade e a elite paraense foi através dos semanários ilustrados:

A (há) gangrena em ambos. A sátira é o cautério mais enérgico, oferece o laborioso crítico. A pena e o lápis, os únicos instrumentos cirúrgicos com que, em nome da medicina moral, abre caminhos a amputação. (...) Cumpre que ela não se mantenha eternamente escrava de paixões ruins, nem dela faça monopólio a especulação política, que, intervendo a missão, constrange-a ao papel de corruptor do sentimento público. (...) Sem compromisso de outra ordem, que o amor da verdade e da justiça, o Estafeta usará do mesmo rigor, quer para gregos quer para troyanos. ( $O$ Estafeta. Belém, 6 de abril de 1897. Ano 01. N. 1).
Entre as críticas estava o comportamento paraense com relação à religiosidade. Em uma série de desenhos que intitulou "vantagens da procissão", Crispim ridicularizou os hábitos de falso moralismo religioso da sociedade. A impressão era feita em pedra litográfica e a tipografia ficava a cargo de A. Campbell. Crispim do Amaral e Campbell ${ }^{7}$ sempre estiveram à frente das causas republicanas e abolicionistas, e através do semanário "empenhouse nas campanhas da reforma social e política, na abolição da escravatura e propaganda republicana" e "foi um dos pioneiros na ilustração na imprensa do Pará" (SALLES, 1992, p. 11).

Com o surgimento da mídia impressa, para Burke (2004), a consciência popular política foi 
estimulada pela difusão de impressos satíricos. Sabe-se que as imagens têm um poder de influência e construção do discurso popular (BURKE, 2004 p. 47). Neste caso, o recurso da mídia é de extrema importância para a dissolução dos pontos de vista hegemônicos. Tanto o Estafeta como a Semana llustrada surgem como meio de contraposição aos grandes jornais, abrindo um caminho para a emancipação do pensamento que detinham estes veículos.

A questão racial também estava incutida abertamente nas páginas de $A$ Semana llustrada. Entre as imagens realizadas por Chrispim do Amaral, a cena abaixo é uma das mais polêmicas para a época. Na imagem, há das representações masculinas, homem negro e um homem branco - ambos estão abraçados e se beijando. Segue a seguinte legenda: "Já recebeste tua carta, agora recebe este abraço; não é por teres cabelo de pimenta-do-reino ${ }^{8}$ que deixaras de ser cidadão. Seja homem". A imagem refere-se aos negros que receberam a carta de alforria, mas não estavam inseridos dentro da sociedade. Vicente Salles (1971) ${ }^{9}$ aponta que grande parte dos libertos se concentrava na capital paraense, mas viviam de maneira marginalizada, em condições precárias.

Os libertos estavam jogados a própria sorte: sem bens e sem empregos, os libertos, dentro de uma cidade ainda com hábitos da colônia, eram tidos como a "classe infame e degredados" (Idem). Antes mesmo da abolição da escravidão, os movimentos abolicionistas desempenharam um papel fundamental para a emancipação do negro ${ }^{10}$. A legenda que Chrispim do Amaral fornece é justamente um discurso que, apesar do preconceito racial perante a sociedade e, por ter recebido a "liberdade de outro", afirma que apesar de todas essas circunstancias é de fato um homem e tem os mesmo direitos e deveres. Para Eugène Enriquez $(2006)^{11}$, a partir do séc. XIX, com o discurso de emancipação e o progresso humano, afirmar-se a ideia de que um indivíduo podia tornar-se um sujeito de direito: sujeitos às suas ações e, sobretudo, que fosse reconhecido como tendo o direito, como ser humano e como cidadão de um país, gozar da totalidade dos direitos acordados ao conjunto dos cidadãos nacionais ou ao conjunto dos homens residentes num território. 0 sujeito de direito era, pois, um indivíduo considerado, respeitado frente a todos

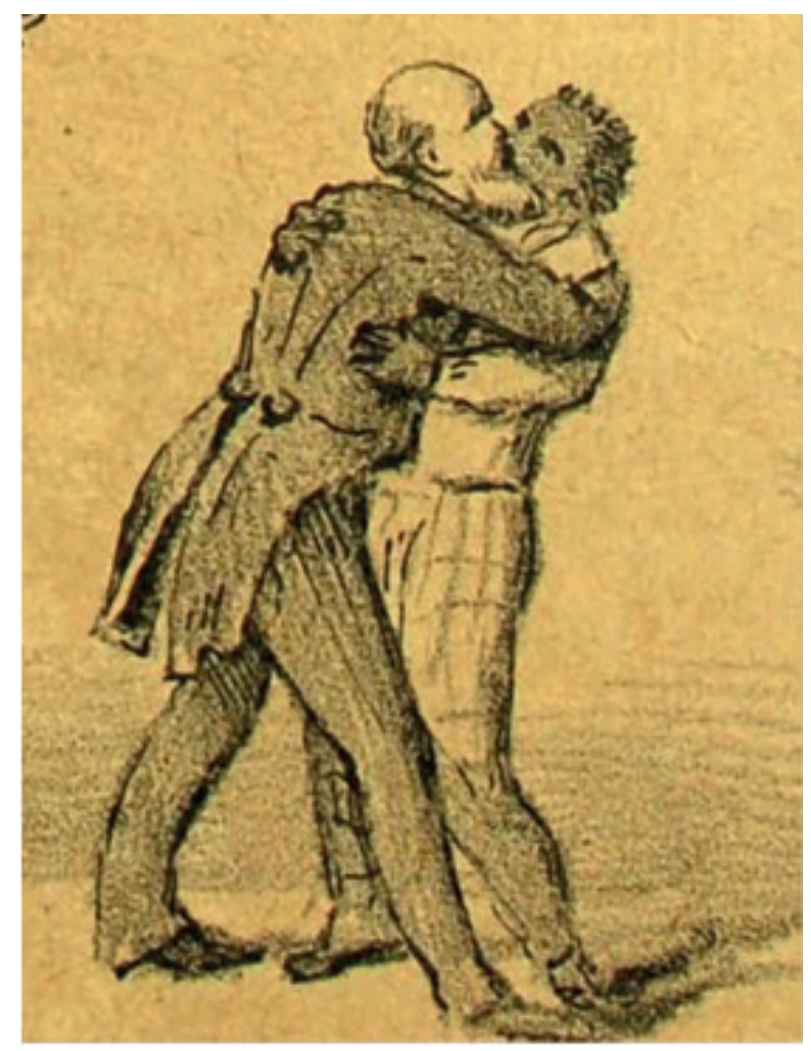

Figura 5 - Detalhe em pormenor. A Semana llustrada, 29 de agosto de 1887. Ano 1, n. 9.

os outros e que estava sob a proteção de uma lei semelhante para todos.

Outra interpretação da imagem acima está ligada ao fato de uma "falsa liberdade" (PALHA, 2011), em sua pesquisa, analisa que as concessões de alforrias na primeira metade do século XIX, fazia parte da política senhorial de domínio ou controle sobre o escravo. A promessa de uma futura liberdade criava uma relação caracterizada pela obediência e fidelidade escrava com o seu "dono", formando assim uma espécie de "controle silencioso sobre os espíritos revoltosos de escravos que anelavam a liberdade" (PALHA, 2011, p. 133 apud TEIXEIRA, 2004, p. 237). Portanto, a carta de alforria, acabou em muitos casos, como uma prática de controle social sobre os escravos.

Sobre a sua obra gráfica presente no Pará, mais especificamente A Semana llustrada (1887-1888), conseguiu alcançar notoriedade na cidade belenense através das caricaturas e do humor de seus textos. Vimos como exploravam com sucesso as temáticas sociais, de políticas públicas, da escravidão e racismo e os hábitos de uma sociedade provinciana. 
Seus ideais políticos (sejam eles referentes ao apoio à monarquia ou à república) nunca foram de fato específicos ${ }^{12}$ - apesar de simpatizar com os ideais republicanos franceses, não se percebeu no conjunto de caricaturas encontradas uma definição clara sobre essa questão. Mas sabe-se que lutava pela causa abolicionista, participando de concertos, carreatas em prol da libertação do homem preso pelos próprios homens.

A sua grande marca contra essa opressão foi o traço, que possibilitou denunciar os maus-tratos contra negros e recém-libertos da escravidão que perdurou durante séculos na história do país. Denunciou e levantou questões contra todos esses problemas como via de formar opiniões. Investigar seu passado é prova viva de uma constante luta contra uma sociedade que favorecia apenas uma elite; Chrispim do Amaral procurou meios emancipatórios para o homem negro do século XIX. Vicente Salles, o grande pesquisador paraense que deixou um legado importantíssimo para a historiografia de artistas negros brasileiros, organizou diversos artigos para o jornal A Província do Pará, intitulado o Traço da troça ou o desenho, de humor no Grão-Pará. Embora não finalizado, este material se encontra organizado e disponível em um volume na Biblioteca do Museu da Universidade do Pará. Salles, com esse trabalho, deixou clara a importância do ativismo de Chrispim do Amaral contra a escravidão no Brasil, ganhando notoriedade através do humor pensante.

As caricaturas realizadas por Amaral sempre eram voltadas para a sátira, mas partes desses desenhos revelam uma "inspiração" aos moldes dos jornais caricatos franceses. A prática da caricatura foi uma arma poderosa contra os sistemas políticos e sociais durante a Revolução Francesa. Aliás, o molde jornalístico com a caricatura foi implementado por Charles Philipon, editor do jornal La Caricature (fundado em 1830) nesse mesmo jornal Chrispim do Amaral trabalhou no ano de 1900 - satirizando políticos e costumes do cotidiano e dando voz a quem precisava.

\section{NOTAS}

1. SALLES, 1992-1993. (Coletânea de escritos reunidos pelo próprio autor).
2. Confundindo o conceito de modernidade com a ideia de contemporaneidade. (OLIVEN, 2001, p. 03).

3. SALLES, 1992. (Coletâneas de escritos reunidos pelo próprio autor)

4. Entre os trabalhos desenvolvidos por Crispim do Amaral destacam-se os panos de bocas pintados para o Teatro Amazonas - A Alegoria do Encontro das Águas (executado aproximadamente e no ano1895); e para o Teatro da Paz - A Alegoria da República (1889).

5. Essa caricatura (Dum-dum) representando a Rainha Vitória não foi a única. Em diversas publicações da revista francesa La Caricature Chrispim do Amaral desenhou jocosamente nas primeiras páginas a Rainha Vitória.

6. Hans-Karl Wiegandt (Colonia 1841 - Belém 1908). Artista litógrafo alemão jornalista e caricaturista. Chegou ao Brasil por volta do ano de 1868, residindo primeiramente em Recife. Iniciou os seus trabalhos como litografo em 1869, associando-se com W. de Melo Lins, fundando o jornal A Careta - de cunho caricato, sendo ilustrado totalmente por Wiegandt. No seguinte, em 1870, muda-se para o Pará para abrir uma empresa de litografia. A permanência de Wiegandt na cidade belenense marcou o surgimento da imprensa ilustrada através da litografia. De Acordo com Martins e tal (2018), Wiegandt foi fundamental para o desenvolvimento da insdustria gráfica paraense. Publicou o semanário dominical o Puraqué (1878), e trabalhou com diversos artistas, imprimindo trabalhos para Crispim do Amaral, Leon Righini. Com o advento da República, Wiedgandt alcançou maior prestígio, sendo nomeado professor de desenho da Escola Normal e fundou a Sociedade Propagadora do Ensino (1895). Faleceu em Belém no ano de 1908. SALLES, 1992.

7. João Archibald Campbell (1840-1924) Jornalista e caricaturista, natural da cidade de Belém é considerado o grande incentivador da caricatura no Grão-Pará. Filho de escoceses inicialmente trabalhou como comerciante, mas se enveredou pelo jornalismo cotidiano, comercial e político. Investiu na publicação e manutenção de vários jornais (SALLES, 1992).

8. Termo pejorativo para referir-se aos cabelos dos meninos, os quais, sempre curto constituíam minúsculos pontinhos pretos separados na cabeça. 
COSTA, Rogéria de Paula. "Não quero ser branca não. Só quero um cabelo bom, cabelo bonito!": performances de corpos/cabelos de adolescentes negras em práticas informais de letramento / Rogéria Costa de Paula. -- Campinas, SP, 2010. Orientador Marilda do Couto Cavalcanti. Tese (doutorado) - Universidade Estadual de Campinas, Instituto de Estudos da Linguagem.

9. SALLES, Vicente. O Negro no Pará. Fundação Getúlio Vargas: Coleção Amazônica. Série José Veríssimo. Universidade Federal do Pará, Belém: 1971.

10. Apesar dos problemas mediante a toda essa situação racial, a massa dos libertos, mostrando as suas insatisfações, chegou a alcançar níveis de politização, chegando até preocupar grandes esferas politicas dentro da sociedade (Idem, p. 304).

\section{ENRIQUEZ (2006).}

12. Deixo essa indagação para o leitor, pois a bolsa de estudos de Chrispim do Amaral fora financiada pela monarquia, além de o artista desenhar e publicar homenagens póstumas para o Imperador Dom Pedro II.

\section{REFERÊNCIAS}

AZEVEdo, Celia Maria Marinho de. Onda Negra Medo Branco: $O$ negro no imaginário das elites no século XIX. Coleção Oficinas de História, vol. 06 ed. Rio de Janeiro: Paz e Terra ed. 1987.

BURKE, Peter. Uma história social da mídia: de Gutemberg à Internet. Rio de Janeiro: Jorge Zahar ed. 2004.

COSTA, Rogéria de Paula. "Não quero ser branca não. Só quero um cabelo bom, cabelo bonito!": performances de corpos/cabelos de adolescentes negras em práticas informais de letramento. Tese de Doutorado, Linguística Aplicada, Instituto de Estudos da Linguagem Universidade Estadual de Campinas, Campinas/SP, 2010.

ENRIQUEZ, Eugène. O homem do século XXI: sujeito autônomo ou indivíduo descartável. ERAeletrônica Fundação Getúlio Vargas, v.5, Artigo n 10, São Paulo, 2006.

FALCÓN, Raúl Gustavo. Um estudo de iconologia do Pano de Boca do Teatro Amazonas, atribuído a Chrispim do Amaral. Trabalho de Conclusão de Curso, Música, Universidade do Estado do Amazonas, Manaus, 2015.

LEITE, José Roberto Teixeira. Pintores Negros do Oitocentos. Rio de Janeiro: E. Emanoel Araújo e Indústria de freios KNORR/MWM motores, 1988.

MESQUITA, Otoni. Manaus História e Arquitetura (1852-1910). 3. ed. Manaus: Editora Valer, 2006.

PALHA, Bárbara da Fonseca. A Escravidão Negra em Belém: mercado, trabalho e liberdade (18101850). Dissertação de Mestrado, História, Instituto de Filosofia e Ciências Humanas, Universidade Federal do Pará, Belém, 2011.

PÁSCOA, Márcio. A Vida Musical em Manaus na Época da Borracha (1850-1910). Manaus: Imprensa Oficial do Estado do Amazonas/ FUNARTE, 1997.

SALLES, Vicente. 0 Negro no Pará. Fundação Getúlio Vargas: Coleção Amazônica. Série José Veríssimo. Universidade Federal do Pará, Belém: 1971.

SALLES, Vicente. 0 traço da troça, ou o desenho de humor no Grão-Pará. Belém. Coleção organizada pelo autor publicadas no jornal A Província do Pará entre os anos de 1992 a 1994. Belém, Acervo Vicente Salles.

SCHWARCZ, Lilia Moritz; CARVALHO, José Murilo de (Org.). História do Brasil Nação: 1808-2010. Volume 2: A construção nacional (1830-1889) - A vida política. Rio de Janeiro: Objetiva, 2012.

SCHWARCZ, Lilia Moritz; SALIBA, Elias Thomé (Org.). História do Brasil Nação: 1808-2010. Volume 3: A abertura para o mundo (1889-1930) - Cultura / as apostas na república. Rio de Janeiro: Objetiva, 2012.

SHAKESPEARE, Willian. Sonho de uma Noite de Verão. Tradução de Jean Melville. Editora Martin Claret: São Paulo, 2005.

\section{PERIÓDICOS}

A Semana llustrada, Belém, 29 de agosto de 1887. Ano 1, n. 9.

Diário de Noticias, Belém 24 de julho de 1883.

Le Petite Journal. Paris 20 de agosto de 1905. 
O Estafeta. Belém 6 de abril de 1879. Ano 01. N.1.

Revista da Semana. Rio de Janeiro 11 de dezembro de 1912. ed. 6.

\section{SOBRE O AUTOR}

Mestre em Letras e Artes (UEA); Graduado em Licenciatura em Música (UEA). Atuou como violinista na Orquestra Barroca do Amazonas 20122018. Participou na gravação de quatro CDs com repertório de música Luso-brasileira dos séculos XVIII e XIX: “Ópera no Brasil colonial", Belém, em 2012; Dramma - Galants Arias and Concerts of the Luso-Brazilian Eigtheenth Century, Lisboa, Portugal, em 2014; CD no Festival Internacional de Música Colonial Brasileira e Música Antiga de Juiz de Fora em 2015; e o quarto CD com repertório do Barroco Colonial Brasileiro, em Goiânia (2017). E-mail: rgustavofalcon@gmail.com 